\title{
EFEITO DA FERTILIZAÇÃO COM FÓSFORO, POTÁSSIO E MAGNÉSIO EM JACATUPÉ INFECTADO COM RIZÓBIO EM UM LATOSSOLO ÁLICO'
}

\author{
NEWTON PEREIRA STAMFORD ${ }^{2}$, CAROLINA ETIENE DE ROSÁLIAE SILVA SANTOS ${ }^{3}$ \\ RUI MEDEIROS ${ }^{3}$ e ANA DOLORES SANTIAGO DE FREITAS ${ }^{3}$
}

\begin{abstract}
RESUMO - Com o objetivo de avaliar o efeito da fertilização com fósforo, potássio e magnésio na fixação do $\mathrm{N}_{2}$ em jacatupé (Pachyrhizus erosus (L.) Urban) cultivado em um Latossolo Amarelo distrófico álico da Zona da Mata de Pernambuco, foi conduzido um experimento inoculando as sementes com a estirpe de Bradyrhizobium sp. NFB 450. Foram aplicadas quatro fórmulas de adubação com potássio e magnésio, na proporção $\left(\mathrm{K}_{2} \mathrm{O}: \mathrm{MgO}\right) 2: 1$, em quantidades crescentes $(0: 0,40: 20,60: 30$ e 80:40 kg ha-1 de $\mathrm{K}_{2} \mathrm{O}$ e $\mathrm{MgO}$, respectivamente) e cinco níveis de fósforo $\left(0,20,40,60\right.$ e $80 \mathrm{~kg} \mathrm{ha}^{-1} \mathrm{de}$ $\mathrm{P}_{2} \mathrm{O}_{5}$ na forma de superfosfato triplo). A produção máxima foi obtida quando aplicou-se $64 \mathrm{~kg} \mathrm{ha}^{-1} \mathrm{de}$ $\mathrm{P}_{2} \mathrm{O}_{5}$. Observou-se efeito significativo para os níveis de $\mathrm{K}_{2} \mathrm{O}-\mathrm{MgO}$, quando em comparação com o tratamento sem $\mathrm{K} \mathrm{e} \mathrm{Mg}$; entretanto, com o aumento da aplicação verificou-se diminuição da produção de matéria seca e do $\mathrm{N}$ total, e aumento do $\mathrm{P}$ total acumulado na parte aérea. O jacatupé respondeu a níveis baixos da fertilização com $\mathrm{P}, \mathrm{K}$ e Mg, e mostrou-se efetivo na fixação do $\mathrm{N}_{2}$, com grande potencial na produção de biomassa.
\end{abstract}

Termos para indexação: Bradyrhizobium, fixação do $\mathrm{N}_{2}$, Pachyrhizus erosus, solo ácido.

\section{EFFECT OF PHOSPHORUS, POTASSIUM AND MAGNESIUM FERTILIZATION ON YAM BEAN INOCULATED WITH BRADYRHIZOBIUM AND GROWING IN AN ALIC LATOSOL SOIL}

\begin{abstract}
In order to evaluate the effects of phosphorus, potassium and magnesium application on the nutrient absorption and yield of yam bean (Pachyrhizus erosus (L.) Urban), in a Yellow Latosol of the Zona da Mata of Pernambuco State, Brazil, an experiment was carried out using the strain of Bradyrhizobium sp. NFB 450, isolated from yam bean and selected for efficient $\mathrm{N}_{2}$ fixation in previous experiments. Potassium and magnesium were applied in the proportion of $2: 1\left(\mathrm{~K}_{2} \mathrm{O}: \mathrm{MgO}\right)$ in increasing levels $\left(0: 0,40: 20,60: 30\right.$ and 80:40 $\mathrm{kg} \mathrm{ha}^{-1}$ of $\mathrm{K}_{2} \mathrm{O}$ and $\mathrm{MgO}$, respectively), and crescent levels of phosphorus $\left(0,20,40,60\right.$ and $80 \mathrm{~kg} \mathrm{ha}^{-1}$ of $\left.\mathrm{P}_{2} \mathrm{O}_{5}\right)$ were added in the form of triple superphosphate. Maximum dry matter production, total $\mathrm{N}$ and total $\mathrm{P}$ accumulated were obtained when applying $64 \mathrm{~kg} \mathrm{ha}^{-1}$ of $\mathrm{P}_{2} \mathrm{O}_{5}$. A significant effect of $\mathrm{K}_{2} \mathrm{O}: \mathrm{MgO}$ levels was observed in relation to the treatment without $\mathrm{K}$ and $\mathrm{Mg}$ application; nevertheless, higher levels of $\mathrm{K}_{2} \mathrm{O}: \mathrm{MgO}$ decreased dry matter and total $\mathrm{N}$, and increased total $\mathrm{P}$ accumulation. Yam bean responded to low levels of $\mathrm{P}, \mathrm{K}$ and $\mathrm{Mg}$ fertilizer, and showed ability in $\mathrm{N}_{2}$ fixation, with great potential for biomass production.
\end{abstract}

Index terms: $\mathrm{N}_{2}$ fixation, Pachyrhizus erosus, acid soil.

\section{INTRODUÇÃO}

As raízes tuberosas do jacatupé (Pachyrhizus erosus (L.) Urban) constituem excelente fonte de amido e, em menor quantidade, vitaminas e proteínas.

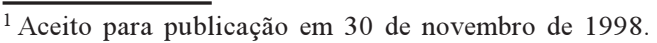

${ }^{2}$ Eng. Agr., Dr., Prof. Titular, Dep. de Agronomia, Universidade Federal Rural de Pernambuco (UFRPE), Rua D. Manoel de Medeiros, s/n. ${ }^{\circ}$, Dois Irmãos, CEP 52171-900 Recife, PE. E-mail: newtonps@novaera.com.br

${ }^{3}$ Eng. Agr., M.Sc., Núcleo de Fixação do $\mathrm{N}_{2}$ nos Trópicos (NFBNT), Dep. de Agronomia, UFRPE
}

Como a batatinha (Solanum tuberosum L.), a mandioca (Manihot esculenta Crantz), e o inhame (Dioscorea $\mathrm{sp}$.), essa leguminosa poderá exercer grande importância na alimentação humana e no arraçoamento de animais, bem como na produção industrial de farinhas ( Zehler et al., 1986; Melo et al., 1994).

Além da produção de tubérculos, sua elevada capacidade de produção de sementes (média de $4 \mathrm{t} \mathrm{ha}^{-1}$ ) tem despertado interesse de pesquisadores (Sales, 1985). Segundo Sales et al. (1990), as sementes de jacatupé contêm teor protéico 
elevado, com solubilidade e composição de aminoácidos semelhantes à soja, e com os seguintes valores: teor de proteína $23,71 \%$ e matérias graxas $23,36 \%$. As sementes apresentam dois princípios tóxicos (rotenona e pachirrizina) que, após extração por processos simples, podem ser empregados como inseticida biológico (Sorensen, 1996).

Em comparação com outras culturas, as plantas tuberosas retiram do solo quantidades relativamente grandes de $\mathrm{N}$ e $\mathrm{K}$, e quantidades menores de $\mathrm{P}, \mathrm{S}$, $\mathrm{Ca}$ e Mg (Perrenoud, 1983). Esse pesquisador ressalta que a fertilidade natural da maioria dos solos destinados ao cultivo de tuberosas não é suficiente para atender às necessidades das culturas: requer adições de nutrientes através de adubações.

De acordo com Siqueira (1988), o solo constitui um excelente ambiente para o crescimento microbiano, pois é um sistema complexo e muito dinâmico, no qual fatores, não apenas de natureza física e química, mas também biológica, interagem contínua e simultaneamente, e modificações em qualquer um desses fatores podem desencadear vários tipos de alterações. $\mathrm{O}$ autor relata que o uso de fertilizantes exerce uma influência muito grande na microbiota do solo e pode atuar não somente na melhoria do estado nutricional das plantas, mas também provocar modificações no metabolismo e no mecanismo de defesa contra doenças.

A cultura do inhame, típica de regiões tropicais, é bastante exigente com relação ao $\mathrm{P}$, em razão da produção e acumulação de amido (Silva, 1983). No entanto, nos estados de Pernambuco e Paraíba, onde o inhame é bastante cultivado, os solos nem sempre apresentam condições ideais de fertilidade. Pelas semelhanças no sistema de cultivo e nas exigências edafoclimáticas com o inhame, acredita-se que 0 jacatupé possa, num futuro próximo, tornar-se uma cultura de exploração econômica nessas regiões.

A presente pesquisa tem como objetivo avaliar o efeito da fertilização com K, Mg e P no jacatupé infectado com estirpes selecionadas de rizóbio e cultivado em um solo ácido da Zona da Mata de Pernambuco, bem como verificar a interação entre esses nutrientes na fixação do $\mathrm{N}_{2}$, na produção de matéria seca e na acumulação de $\mathrm{N}, \mathrm{P}, \mathrm{K}$ e Mg na parte aérea.

\section{MATERIAL E MÉTODOS}

O experimento foi realizado com amostras superficiais de um solo classificado como Latossolo Amarelo distrófico álico textura média (Brasil, 1972/1973), do município de Igarassu, Zona da Mata do Estado de Pernambuco. As análises químicas e físicas das amostras do solo foram realizadas de acordo com a metodologia da Embrapa (1997) e apresentaram os seguintes resultados: $\mathrm{pH}$ em $\mathrm{H}_{2} \mathrm{O}$ 5,9; cátions trocáveis $\left(\mathrm{mmol}_{\mathrm{c}} \mathrm{kg}^{-1}\right)$ : $\mathrm{K}^{+}, 0,6 ; \mathrm{Ca}^{2+}, 15,0 ; \mathrm{Mg}^{2+}, 6,0 \mathrm{e} \mathrm{Al}^{3+}, 0,5 ; \mathrm{P}$ extraível (Mehlich), 2,9 mg kg-1; $\mathrm{N}$ total, 1,5 $\mathrm{g} \mathrm{kg}^{-1}$; $\mathrm{C}$ orgânico, $14,1 \mathrm{~g} \mathrm{~kg}^{-1}$; densidade global, $2,65 \mathrm{~g} \mathrm{~cm}^{-3}$; densidade das partículas, $1,59 \mathrm{~g} \mathrm{~cm}^{-3}$; areia grossa, $65 \%$; areia fina, $20 \%$; silte, $9 \%$ e argila, $6 \%$; classificação textural: areia franca.

$\mathrm{O}$ delineamento experimental adotado foi em blocos ao acaso, com os tratamentos em arranjo fatorial $4 \times 5$, constituído de três blocos. Os tratamentos consistiram de cinco níveis de $\mathrm{P}$ equivalentes a $0,20,40,60$ e $80 \mathrm{~kg} \mathrm{ha}^{-1}$ de $\mathrm{P}_{2} \mathrm{O}_{5}$ e quatro fórmulas de adubação com $\mathrm{K}$ e Mg. As fórmulas apresentaram a relação $\mathrm{K}_{2} \mathrm{O}: \mathrm{MgO}$ de 2:1, com base nos resultados obtidos por Figueiredo et al. (1996), aplicadas nas seguintes quantidades em $\mathrm{kg} \mathrm{ha}^{-1}$ : 0:0; 40:20; 60:30; 80:40. Como fonte de P empregou-se o superfosfato triplo, e como fonte de $\mathrm{K}$ e Mg, usou-se o fertilizante comercial sulfato duplo de potássio e magnésio contendo $22 \%$ de $\mathrm{K}_{2} \mathrm{O}$ e $11 \%$ de $\mathrm{MgO}$, ou seja, na proporção 2:1

O solo foi secado ao ar, passado em peneira $(5,0 \mathrm{~mm})$, misturado, e colocados $6,0 \mathrm{~kg}$ por vaso de polietileno. Para controle da umidade, colocou-se em cada vaso um dreno de plástico e uma camada de brita fina com $2 \mathrm{~cm}$ de espessura, adicionando-se água diariamente, até as primeiras gotas serem drenadas pelo sistema.

Os micronutrientes foram fornecidos adicionando-se $2 \mathrm{~mL} \mathrm{~kg}{ }^{-1}$ de solo, de uma solução contendo por litro $15,8 \mathrm{~g}$ de $\mathrm{CuSO}_{4} \cdot 5 \mathrm{H}_{2} \mathrm{O} ; 20 \mathrm{~g}$ de $\mathrm{FeSO}_{4} \cdot 7 \mathrm{H}_{2} \mathrm{O} ; 8,9 \mathrm{~g}$ de $\mathrm{ZnSO}_{4} \cdot 7 \mathrm{H}_{2} \mathrm{O} ; 1,0 \mathrm{~g}$ de $\mathrm{H}_{3} \mathrm{BO}_{3} ; 0,7 \mathrm{~g}$ de $\mathrm{NaMoO}_{4} \cdot 2 \mathrm{H}_{2} \mathrm{O}$ e $20 \mathrm{~g}$ de ácido cítrico

A estirpe de Bradyrhizobium utilizada foi a NFB 450, isolada de jacatupé que crescia em solo da região de Itambé (Zona da Mata de Pernambuco), e avaliada como de boa eficiência na capacidade de fixação do $\mathrm{N}_{2}$, em experimentos anteriores (Stamford et al., 1994). No preparo do inoculante, a estirpe foi purificada por repicagem para placas-de-petri com meio ágar, manitol e extrato de levedura (YEMA), como descrito por Vincent (1970). A seguir, a estirpe foi repicada em frascos erlenmeyer de $125 \mathrm{~mL}$ com meio manitol, extrato de levedura (YEMA) e mantida em agitador rotativo, em temperatura ambiente $\left(28^{\circ} \mathrm{C}\right)$ durante cinco dias. A inoculação foi realizada com $1 \mathrm{~mL}$ de cultura líquida por semente. 
As sementes de jacatupé foram desinfetadas em álcool $95^{\circ} \mathrm{GL}$ por três minutos, e em $\mathrm{HgCl}_{2}$ (1:500), sendo em seguida lavadas sete vezes com água fervida. Na semeadura foi aberto um sulco (na parte central do vaso), $\operatorname{com} 2 \mathrm{~cm}$ de profundidade, onde foram colocadas quatro sementes, distantes $4 \mathrm{~cm}$ entre si. Os fertilizantes foram colocados em dois sulcos, $5 \mathrm{~cm}$ abaixo e ao lado das sementes. Dez dias após a semeadura procedeu-se ao desbaste deixandose duas plantas por vaso.

A colheita foi realizada 90 dias após a semeadura, sendo as plantas (parte aérea) conduzidas para secagem em estufa, à temperatura de $65^{\circ} \mathrm{C}$, por um período de 72 horas, e, em seguida, determinou-se o peso da matéria seca. Posteriormente, a parte aérea foi moída em moinho tipo Willey (peneira de malha $2 \mathrm{~mm}$ ). Para a determinação do N-total, empregou-se o método Kjeldahl; o K foi determinado por fotometria de chama, o $\mathrm{Ca}$, e o $\mathrm{Mg}$ por espectrofotometria de absorção atômica, e o $\mathrm{P}$, por colorimetria, pelo método do metavanadato, como descritos por Malavolta et al. (1989).

A análise de variância foi realizada de acordo com o delineamento e com o arranjo de tratamentos adotados. A complementação da análise estatística utilizada quanto ao fator fórmulas de adubação foi o teste de Tukey a 5\%, e quanto ao fator níveis de $\mathrm{P}$, utilizou-se análise de regressão polinomial, em que se estudou os componentes linear, quadrático, e o desvio de regressão

\section{RESULTADOS E DISCUSSÃO}

Na Tabela 1 são apresentados os resultados de $\mathrm{K}$ total acumulado na parte aérea do jacatupé, como conseqüência dos tratamentos com os níveis crescentes das fórmulas de adubação com $\mathrm{K} \mathrm{e} \mathrm{Mg} \mathrm{e}$ dos níveis de $\mathrm{P}$, onde pode-se observar que na ausência de $\mathrm{P}$ não houve resposta significativa entre as fórmulas de adubação com $\mathrm{K} \mathrm{e} \mathrm{Mg}$. Esses resultados são explicados pelo baixo nível de $\mathrm{P}$ disponível no solo usado, o que, provavelmente, limitou o crescimento das plantas e interferiu no efeito da adubação com $\mathrm{P}$ e $\mathrm{Mg}$ na quantidade de $P$ total acumulado no jacatupé.

Com relação às doses de 40,60 e $80 \mathrm{~kg} \mathrm{ha}^{-1}$ de $\mathrm{P}_{2} \mathrm{O}_{5}$, verificou-se que não houve diferença significativa entre os níveis de adubação com $\mathrm{K}$ e $\mathrm{Mg} 40-20,60-30$ e 80-40 $\mathrm{kg} \mathrm{ha}^{-1}$ de $\mathrm{K}_{2} \mathrm{O}-\mathrm{MgO}$, no que diz respeito ao $\mathrm{K}$ total acumulado no jacatupé. Porém, essas fórmulas apresentam valores maiores e significativos comparados com o tratamento sem adubo. Observou-se efeito significativo dos níveis de P na acumulação de K (Fig. 1) com acumulação de $124,64 \mathrm{mg}_{\text {planta }}{ }^{-1}$, quando aplicados $80 \mathrm{~kg} \mathrm{ha}^{-1} \mathrm{de}$ $\mathrm{P} \mathrm{e}$ apenas $22,84 \mathrm{mg}$ planta $^{-1}$ para o tratamento sem adição de $\mathrm{P}$.

As análises de regressão referentes aos níveis de $\mathrm{P}$ em interação com as diferentes fórmulas de adubação com K e Mg são apresentadas na Fig.1. Os resultados mostram que houve resposta positiva e quadrática da quantidade de $\mathrm{K}$ total acumulado no jacatupé, com os seguintes pontos máximos: $76 \mathrm{mg}$ planta $^{-1}$ para o nível $0-0 ; 142 \mathrm{mg}$ planta $^{-1}$ para 40-20; e $140 \mathrm{mg}$ planta $^{-1}$ para 80-40.

Na Tabela 2 observa-se que o jacatupé não apresentou diferença significativa na acumulação de $P$ total, em relação às fórmulas de adubação. Entretanto, as quantidades de $\mathrm{P}$ total acumulado cresceram à medida que se elevaram as doses de $\mathrm{Ke}$ de $\mathrm{Mg}$ no solo. Resultados com a mesma tendência foram encontrados por Stamford et al. (1980), em caupi.

TABELA 1. Efeito da fertilização com potássio $\left(\mathrm{K}_{2} \mathrm{O}\right)$ e magnésio $(\mathrm{MgO})$ (relação 2:1), na acumulação de potássio na parte aérea de jacatupé, em conseqüência da adição de níveis de fósforo ${ }^{1}$.

\begin{tabular}{|c|c|c|c|c|c|}
\hline \multirow{2}{*}{$\begin{array}{c}\text { Nível } \\
\mathrm{K}_{2} \mathrm{O}-\mathrm{MgO}\end{array}$} & \multicolumn{5}{|c|}{ Níveis de $\mathrm{P}_{2} \mathrm{O}_{5}\left(\mathrm{~kg} \mathrm{ha}^{-1}\right)$} \\
\hline & 0 & 20 & 40 & 60 & 80 \\
\hline$\left(\mathrm{kg} \mathrm{ha}^{-1}\right)$ & - n & 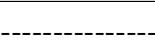 & $\left(\mathrm{mg} \mathrm{planta}^{-1}\right)$ & & \\
\hline $0-0$ & $15,93 \mathrm{aB}$ & $55,24 \mathrm{bA}$ & $70,93 \mathrm{bA}$ & $66,63 \mathrm{bA}$ & $76,06 \mathrm{bA}$ \\
\hline $40-20$ & $23,56 \mathrm{aD}$ & $87,93 \mathrm{abC}$ & $127,46 \mathrm{aB}$ & $143,30 \mathrm{aA}$ & $129,06 \mathrm{aB}$ \\
\hline $60-30$ & $27,13 \mathrm{aC}$ & $108,76 \mathrm{aB}$ & $125,00 \mathrm{aAB}$ & $122,33 \mathrm{aAB}$ & $142,63 \mathrm{aA}$ \\
\hline $80-40$ & $24,73 \mathrm{aC}$ & $82,30 \mathrm{abB}$ & $135,00 \mathrm{aA}$ & $123,20 \mathrm{aAB}$ & $150,82 \mathrm{aA}$ \\
\hline
\end{tabular}

${ }_{1}^{1}$ Médias seguidas da mesma letra, minúscula nas colunas e maiúscula nas linhas, não diferem estatisticamente pelo teste de Tukey, a $5 \%$ de probabilidade; C. $\mathrm{V} .=18 \%$. 

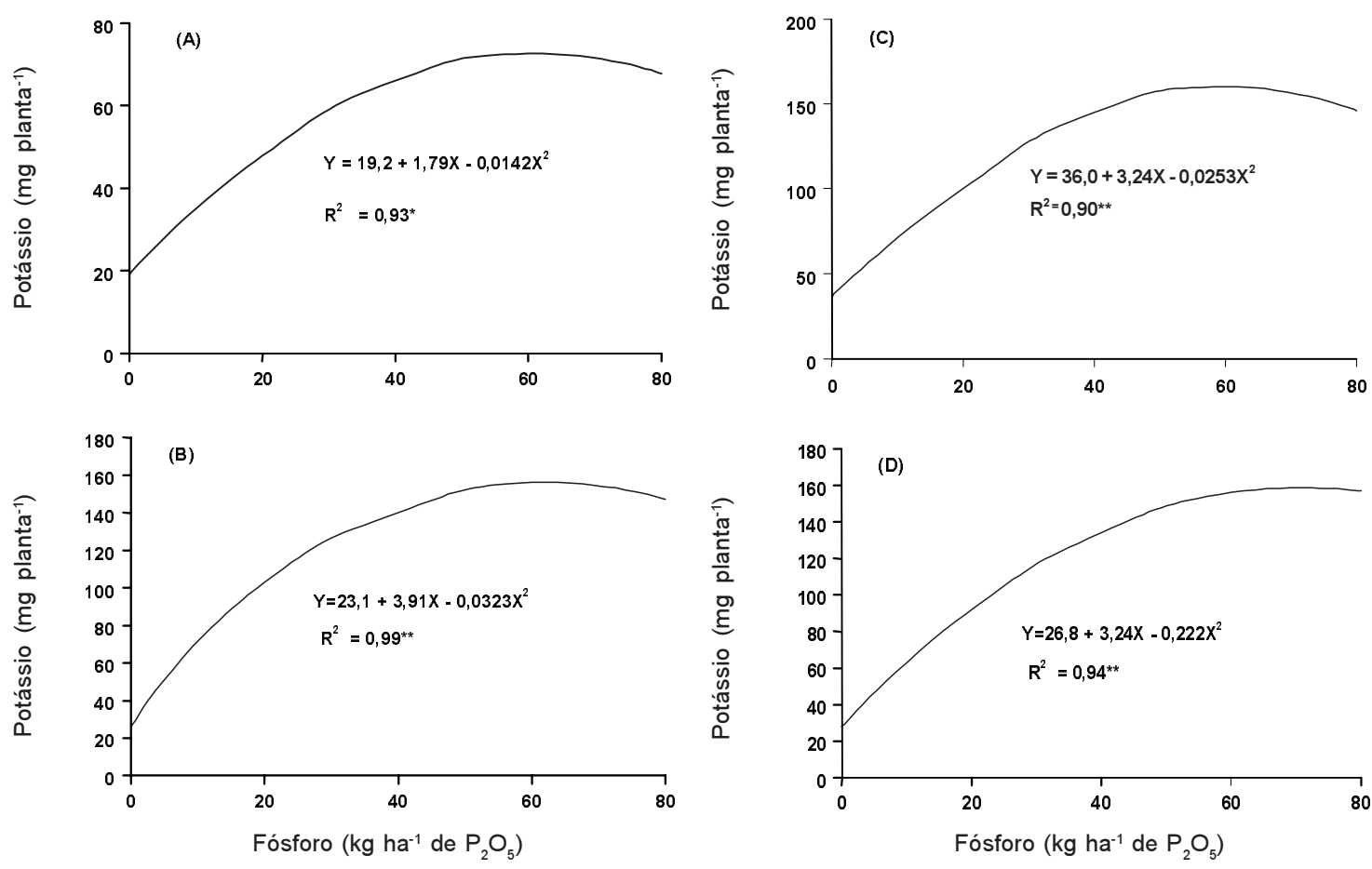

FIG. 1. Regressão entre $P\left(\mathrm{~kg} \mathrm{ha}^{-1}\right.$ de $\left.P_{2} O_{5}\right)$ e $K$ total acumulado (mg planta $\left.{ }^{-1}\right)$, na parte aérea de jacatupé cultivado em um Latossolo Amarelo, na ausência de $\mathrm{K}$ e $\mathrm{Mg}$ (A) e com aplicação de $\mathrm{K}_{2} \mathrm{O}$-MgO $\left(\mathrm{kg} \mathrm{ha}^{-1}\right)$ nos níveis de 40-20 (B), de 60-30 (C) e de 80-40 (D).

TABELA2. Efeito da fertilização com potássio $\left(\mathrm{K}_{2} \mathrm{O}\right)$ e magnésio (MgO) (relação 2:1), na acumulação de nitrogênio, fósforo, cálcio e magnésio, e na produção de matéria seca da parte aérea do jacatupé1.

\begin{tabular}{|c|c|c|c|c|c|}
\hline \multirow{2}{*}{$\begin{array}{c}\text { Nível } \\
\mathrm{K}_{2} \mathrm{O}-\mathrm{MgO}\end{array}$} & \multicolumn{4}{|c|}{ Nutriente acumulado } & \multirow{2}{*}{$\begin{array}{c}\text { Matéria seca da } \\
\text { parte aérea }\end{array}$} \\
\hline & Fósforo & Cálcio & Magnésio & Nitrogênio & \\
\hline$\left(\mathrm{kg} \mathrm{ha}^{-1}\right)$ & - & n & $\left.l^{-1}\right)$ & & $\left(\right.$ g planta $\left.^{-1}\right)$ \\
\hline $0-0$ & $2,60 \mathrm{a}$ & $59,3 \mathrm{a}$ & $12,2 b$ & $94,8 \mathrm{a}$ & $3,75 b$ \\
\hline $40-20$ & $2,97 \mathrm{a}$ & $48,2 b$ & $18,2 \mathrm{a}$ & $107,3 \mathrm{a}$ & $4,83 \mathrm{a}$ \\
\hline $60-30$ & $2,94 \mathrm{a}$ & $39,3 \mathrm{bc}$ & $18,1 \mathrm{a}$ & $101,7 \mathrm{a}$ & $4,51 \mathrm{ab}$ \\
\hline $80-40$ & $3,04 \mathrm{a}$ & $32,7 \mathrm{c}$ & $18,2 \mathrm{a}$ & $98,7 \mathrm{a}$ & $4,42 \mathrm{ab}$ \\
\hline C.V. $(\%)$ & 21 & 24 & 22 & 21 & 17 \\
\hline
\end{tabular}

${ }^{1}$ Médias seguidas da mesma letra, na vertical, não diferem estatisticamente pelo teste de Tukey, a 5\% de probabilidade.

As respostas do jacatupé aos níveis de P são apresentadas na Fig. 2. Quanto ao P total acumulado na parte aérea, os resultados mostram que a absorção cresceu de forma quadrática. O melhor nível de $\mathrm{P}_{2} \mathrm{O}_{5}$ foi $90 \mathrm{~kg} \mathrm{ha}^{-1}$, que proporcionou um ponto máximo de 5,01 mg planta ${ }^{-1}$ de $\mathrm{P}$ total acumulado. Resultados concordantes foram encontrados por Jones \& Freitas (1970) com Stylosanthes e
Centrosema. Fontes \& Fontes (1990), trabalhando com batatinha, mostraram que a concentração de $\mathrm{P}$ nas folhas cresceu de forma linear, com o aumento da adubação fosfatada no solo.

Na Tabela 2 verifica-se que houve resposta significativa do jacatupé no acúmulo de $\mathrm{Mg}$, às fórmulas de adubação, quando comparado com o tratamento sem adubo. Quanto aos tratamentos com as diferen- 

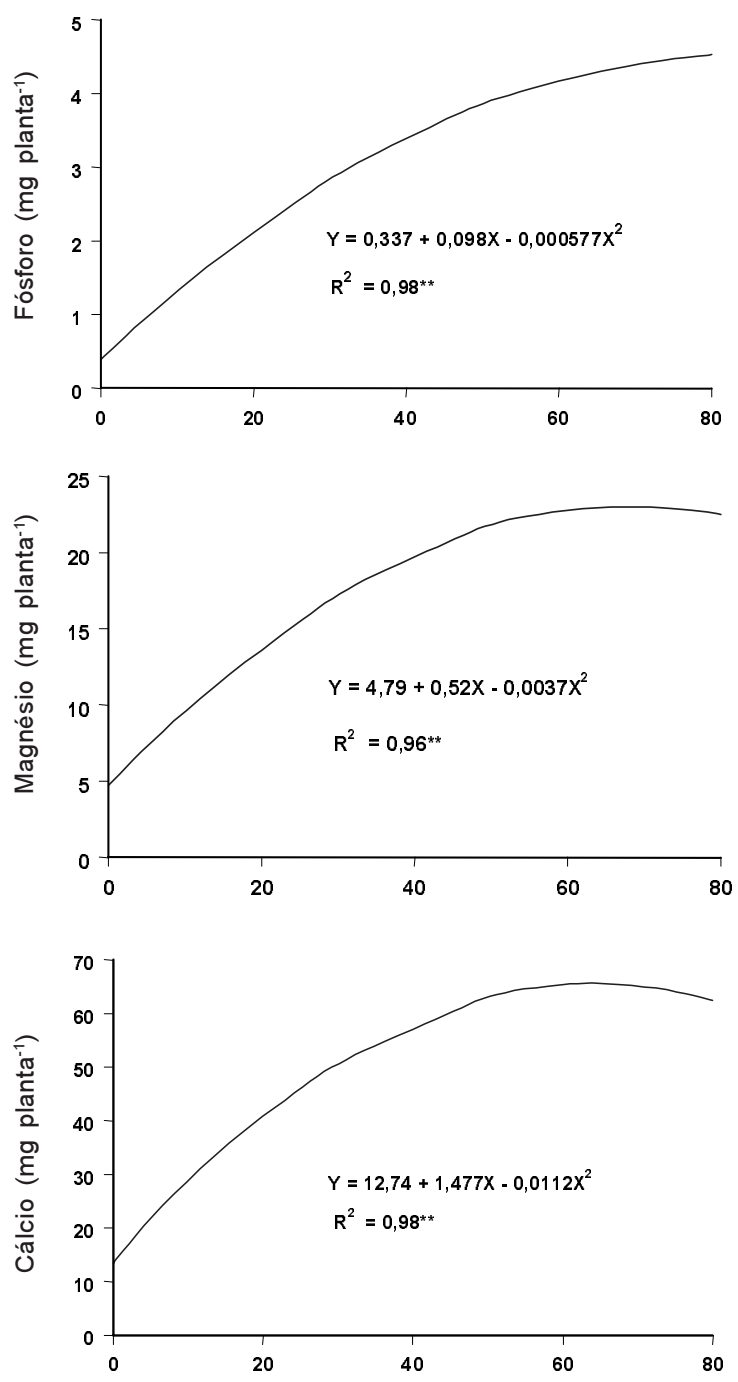

Fósforo ( $\mathrm{kg} \mathrm{ha}^{-1}$ de $\left.\mathrm{P}_{2} \mathrm{O}_{5}\right)$

FIG. 2. Regressão entre $P\left(k^{2}\right.$ ha ${ }^{-1}$ de $\left.P_{2} O_{5}\right)$ e $P$ total $\left(\mathrm{mg} \mathrm{planta}^{-1}\right)$, Mg total (mg planta $\left.{ }^{-1}\right)$ e Ca total (mg planta $\left.{ }^{-1}\right)$ na parte aérea de jacatupé cultivado em um Latossolo Amarelo.

tes fórmulas $\mathrm{K}_{2} \mathrm{O}-\mathrm{MgO}$, os resultados de $\mathrm{Mg}$ total acumulado foram semelhantes. Isto deve-se, provavelmente, ao equilíbrio $\mathrm{K}_{2} \mathrm{O}-\mathrm{MgO}$ nas fórmulas (relação 2:1). Com relação ao tratamento sem adubo $\mathrm{K}_{2} \mathrm{O}-\mathrm{MgO}$, verifica-se que, em média, apresentou uma quantidade de $\mathrm{Mg}$ total acumulado 33\% inferior àqueles com adubo. De acordo com tais resultados, pode-se deduzir que o teor de $\mathrm{Mg}$ no solo estudado estava abaixo do nível crítico no que respeita ao jacatupé, e que a dose de $20 \mathrm{~kg} \mathrm{ha}^{-1}$ de $\mathrm{Mg}$ foi suficiente para mostrar resposta à adubação com esse nutriente, desde que mantidas condições de equilíbrio com $\mathrm{K}$.

Com relação ao efeito dos níveis crescentes de $\mathrm{P}$ na acumulação de $\mathrm{Mg}$ total, verifica-se que houve resposta positiva e quadrática (Fig. 2), com ponto máximo de $23 \mathrm{mg} \mathrm{planta}^{-1}$. Esses resultados foram semelhantes aos observados em mandioca por Paula et al. (1985). Segundo Malavolta (1980), o efeito positivo do $\mathrm{P}$ na absorção do $\mathrm{Mg}$ pode estar relacionado com o efeito sinergético entre $\mathrm{P}$ e $\mathrm{Mg}$, como também foi observado por Stamford et al. (1990), em caupi.

Na Tabela 2 observa-se uma diminuição significativa na quantidade de Ca total acumulado no jacatupé, de acordo com as diferentes fórmulas de adubação usadas. Como esperado, à medida que foram aumentadas as doses de $\mathrm{K}$ e $\mathrm{Mg}$ nas fórmulas de adubação, foram acentuados os efeitos antagônicos desses cátions, na absorção do Ca. Resultados semelhantes foram encontrados em várias pesquisas (Rosolem et al., 1984; Ohno \& Grunes, 1985; Alves et al., 1988).

Em relação aos níveis de $\mathrm{P}$, a análise de regressão (Fig. 2) mostra que houve resposta positiva e quadrática para a quantidade de Ca total acumulado no jacatupé, no ponto máximo de $62 \mathrm{mg}_{\text {planta }}{ }^{-1}$. Resultados com a mesma tendência foram obtidos em mandioca (Paula et al., 1985). De acordo com Pushpadas \& Aiyer (1976), citados por Paula et al. (1985), o superfosfato deve ser considerado como fonte de $\mathrm{Ca}$, o que explicaria o aumento no teor de $\mathrm{Ca}$ no solo quando se usou essa fonte de adubo fosfatado.

Na Tabela 2 observa-se que, em relação ao $\mathrm{N}$ total acumulado na parte aérea do jacatupé, não houve diferença significativa entre os tratamentos com e sem adição do fertilizante com $\mathrm{K}$ e $\mathrm{Mg}$. No tratamento sem fertilização, verifica-se uma menor quantidade de $\mathrm{N}$ total acumulado (94,8 $\left.\mathrm{mg}_{\text {planta }}{ }^{-1}\right)$, e no nível $40-20 \mathrm{~kg} \mathrm{ha}^{-1}\left(\mathrm{~K}_{2} \mathrm{O}-\mathrm{MgO}\right)$, a maior quantidade (107,31 mg planta-1 ${ }^{-1}$. À medida que os níveis de $\mathrm{K}$ e $\mathrm{Mg}$ aumentaram, foi verificada uma diminuição das quantidades de $\mathrm{N}$ total acumulado. Stamford 
et al. (1980), com caupi, também verificaram que a aplicação de doses elevadas de $\mathrm{K}$ diminuiu a quantidade de N total acumulado. Stamford \& Silva (1981), também trabalhando com caupi, observaram que 0 aumento das doses de $\mathrm{Mg}$ aplicadas aumentou a quantidade de $\mathrm{N}$ total acumulado.

Em relação aos níveis de $\mathrm{P}$, a análise de regressão (Fig. 3) apresenta uma resposta positiva e quadrática para a quantidade de $\mathrm{N}$ total acumulado no jacatupé, com ponto máximo de $137,7 \mathrm{mg} \mathrm{planta}^{-1}$. Tais resultados são concordantes com os obtidos por Figueiredo et al. (1996) trabalhando com jacatupé cultivado no mesmo solo usado neste trabalho, e tendência semelhante foi encontrada por Carvalho et al. (1988) com Centrosema e Stylosanthes.

Quanto à produção de matéria seca na parte aérea (Tabela 2), verifica-se que só houve diferença significativa quando comparado o nível 40-20 $\left(\mathrm{K}_{2} \mathrm{O}-\mathrm{MgO}\right)$ com o tratamento sem fertilização $\mathrm{K}$ e Mg. Quando o nível de $\mathrm{K}_{2} \mathrm{O}-\mathrm{MgO}$ foi aumentado, observou-se diminuição no peso de matéria seca da parte aérea, inclusive com valores estatisticamente iguais aos do tratamento sem adubo. Esses resultados apresentam certa semelhança com os observados por Rosolem et al. (1984), com sorgo. Por outro lado, discordam dos obtidos por Lima et al. (1981) na produção de matéria seca do tomateiro. Esses resultados devem-se, provavelmente, ao fenômeno conhecido como consumo de luxo, condição em que a concentração de $\mathrm{K}$ aumenta, e não mostra correlação com a produção de matéria seca (Malavolta, 1976).

A resposta do jacatupé aos níveis de $\mathrm{P}$ apresentada na Fig. 3 mostra que houve um acentuado incremento na produção de matéria seca. Os dados de produtividade (y) e de níveis de $\mathrm{P}$ aplicados (x) ajustaram-se melhor a uma curva quadrática, e através da derivada da equação encontrou-se o nível de $64 \mathrm{~kg} \mathrm{ha}^{-1} \mathrm{de}_{2} \mathrm{O}_{5}$, que proporcionou a produtividade máxima esperada de 5,76 $\mathrm{g}_{\text {planta }}{ }^{-1}$, superior em $400 \%$ à produtividade do tratamento que não recebeu $\mathrm{P}$.

Fontes et al. (1987), trabalhando com batatinha, mostram que o peso de matéria seca das folhas cresce linearmente com o aumento dos níveis de $\mathrm{P}$. Matias (1989) relata que a dose de $60 \mathrm{~kg} \mathrm{ha}^{-1}$ de $\mathrm{P}_{2} \mathrm{O}_{5}$ proporciona melhor produtividade na cultura do inhame.
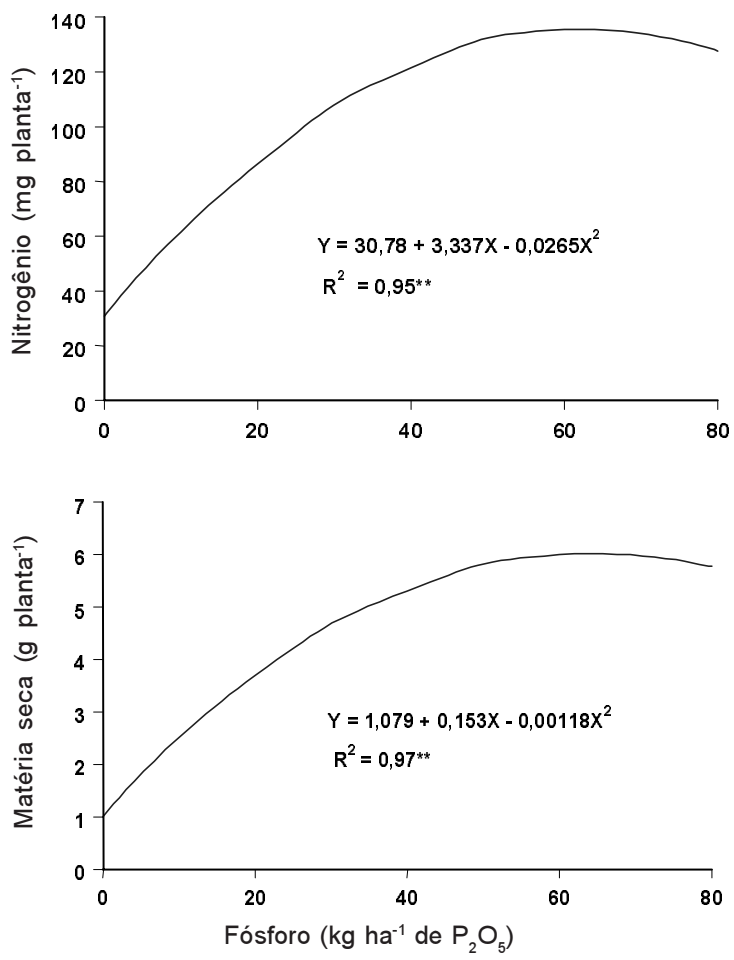

FIG. 3. Regressão entre $P$ e $N$ total (mg planta $\left.{ }^{-1}\right)$ e entre $\mathbf{P}$ e matéria seca (g planta $\left.{ }^{-1}\right)$ na parte aérea de jacatupé cultivado em um Latossolo Amarelo.

Caballero et al. (1987), trabalhando com feijão, mostram que o P é o nutriente que apresenta maior resposta, chegando a triplicar a produção de matéria seca da parte aérea e duplicar a das raízes.

\section{CONCLUSÕES}

1. A adubação fosfatada, a partir do nível $20 \mathrm{~kg} \mathrm{ha}^{-1} \mathrm{de}_{2} \mathrm{P}_{2} \mathrm{O}_{5}$ mostra efeito significativo na matéria seca da parte aérea do jacatupé, com produção máxima no nível $64 \mathrm{~kg} \mathrm{ha}^{-1}$.

2. O jacatupé responde à adição de $\mathrm{Ke} \mathrm{Mg}$, quando cultivado em solo ácido, a partir do nível $\mathrm{K}_{2} \mathrm{O}: \mathrm{MgO}$ de 40:20 $\left(\mathrm{kg} \mathrm{ha}^{-1}\right)$.

3. Em solo ácido, com aplicação de baixos níveis de $\mathrm{P}, \mathrm{K}$ e Mg, o jacatupé submetido à inoculação do rizóbio efetivo extrai nutrientes para aumentar a produção de matéria seca. 


\section{REFERÊNCIAS}

ALVES, A.C.; BRAUNER, J.L.; CORDEIRO, D.S.; ZONTA, E.P.; CORREA, L.A.V. Exigências nutricionais em potássio, cálcio e magnésio do sorgo sacarino. Pesquisa Agropecuária Brasileira, Brasília, v.23, n.5, p.529-536, maio 1988.

BRASIL. Ministério da Agricultura. Departamento Nacional de Pesquisa Agropecuária. Divisão de Pesquisa Pedológica. Levantamento exploratório - reconhecimento de solos do Estado de Pernambuco. Recife, 1972/1973. 2v. (DNPEA. Boletim técnico, 26; DRN - SUDENE. Série Pedológica, 14)

CABALLERO, S.U.; STEFANELLI, D.; OLIVEIRA, C de; VIDAL, R. Necessidades de nutrientes e calagem na produção de matéria seca do feijoeiro num Latossolo Vermelho-Amarelo da Região de Barretos, São Paulo. Pesquisa Agropecuária Brasileira, Brasília, v.22, n.4, p.387-391, abr. 1987

CARVALHO, M.M.; SARAIVA,O.F.; OLIVEIRA, F.T.T.; MARTINS, C.E. Respostas de leguminosas forrageiras tropicais à calagem e ao fósforo, em casa de vegetação. Revista Brasileira de Ciência do Solo, Campinas, v.12, p.153-159, 1988

EMBRAPA. Centro Nacional de Pesquisa do Solo. (Rio de Janeiro, RJ). Manual de métodos de análise do solo. 2.ed. Rio de Janeiro, 1997. 212p.

FIGUEIREDO, M.V.B.; MEDEIROS; R.; STAMFORD, N.P.; SANTOS, C.E.R.S. Efeito da adubação com diferentes relações de potássio/magnésio no jacatupé em Latossolo Amarelo com e sem inoculação com Bradyrhizobium sp. Revista Brasileira de Ciência do Solo, Campinas, v.20, p.49-54, 1996.

FONTES, P.C.R.; FONTES, R.R. Efeito da aplicação de fósforo no solo e nas folhas sobre a produtividade da batata. Revista Ceres, Viçosa, v.38, n.216, p.159169,1990

FONTES, P.C.R.; PAULA, M.B.; MIZUBUTI, A. Produtividade de batata sob a influência de níveis do fertilizante 4-14-8 e do superfosfato simples. Revista Ceres, Viçosa, v.34, n.191, p.90-98, 1987.

JONES, M.B.; FREITAS, L.M.M. de. Respostas de quatro leguminosas tropicais a fósforo, potássio e calcário num Latossolo Vermelho-Amarelo de Campo Cerrado. Pesquisa Agropecuária Brasileira:
Série Agronomia, Rio de Janeiro, v.5, n.3 p.91-99, 1970

LIMA, J.A.; DEFELIPO, B.V.; NOVAIS, R.F.; THIÉBAULT, J.T.L. Efeito das relações $\mathrm{Ca} / \mathrm{Mg}$ e $(\mathrm{Ca}+\mathrm{Mg})$ na correção da acidez de dois Latossolos e na produção de matéria seca do tomateiro (Lycopersicum esculentum, Mill.) cv. "Kada". Revista Ceres, Viçosa, v.28, n.156, p.103-115, 1981.

MALAVOLTA, E. Elementos de nutrição mineral de plantas. São Paulo: Ceres, 1980. 251p.

MALAVOLTA, E. Manual de química agrícola - nutrição mineral de plantas e fertilidade do solo. São Paulo: Ceres, 1976. 528p

MALAVOLTA, E.; VITTI, G.C.; OLIVEIRA, S.A. de. Avaliacão do estado nutricional das plantas princípios e aplicações. Piracicaba: POTAFOS, 1989 $201 \mathrm{p}$

MATIAS, E.C. Adubação mineral e orgânica na cultura do inhame (Dioscorea cayannensis Lam) em podzólico vermelho amarelo. Recife: UFRPE, 1989. 72p. Dissertação de Mestrado.

MELO, E. de A.; KRIEGER, N.; STAMFORD, T.L.M Physico-chemical properties of yam bean (Pachyrhizus erosus L. Urban). Starch, v.46, n.7, p.245-247, 1994.

OHNO, T.; GRUNES, D.L. Potassium-magnesium interactions affecting nutrient uptake by wheat forage. Soil Science Society of America. Journal, v.49, p.685-690, 1985.

PAULA, M. B.; NOGUEIRA, F.A.; TANAKA, R.T. Efeitos de níveis de fósforo e calcário sobre a cultura da mandioca (Manihot esculentum Crantz). Revista Brasileira da Mandioca, Cruz das Almas, v.4, n.2, p.7-18, 1985.

PERRENOUD, S. Potato: Fertilizers for yield and quality. Berne: International Potash Institute, 1983. 84p. (IPI. Bulletin, 8).

ROSOLEM, C.A.; MACHADO, J.R.; BRINHOLI, O. Efeito das relações $\mathrm{Ca} / \mathrm{Mg}, \mathrm{Ca} / \mathrm{K}$ e $\mathrm{Mg} / \mathrm{K}$ do solo na produção de sorgo sacarino. Pesquisa Agropecuária Brasileira, Brasília, v.19, n.12, p.1443-1448, dez. 1984

SALES, A.M. O jacatupé (Pachyrhizus tuberosus Spreng): uma fonte potencial de proteína, óleo e amido. Boletim do ITAL, Campinas, v.22, n.3, p.331-340, 1985

Pesq. agropec. bras., Brasília, v.34, n.10, p.1831-1838, out. 1999 
SALES, A.M.; BALDINI, V.L.S.; CUNHA, M.F.; HENRIQUES, E.A. Perfil eletroforético e composição de aminoácidos de sementes de jacatupé (Pachyrhizus tuberosus Spreng). Ciência e Tecnologia de Alimentos, v.10, n.1, p.87-108, 1990

SILVA, A.A. da. Cultura do cará da costa (Dioscorea cayannensis Lam.) var. Rotundata Poir. 2.ed. Fortaleza: BNB/ETENE, 1983. 171p.

SIQUEIRA, J.O. Microrganismos de solo e seus processos: irrelevantes para a produtividade agrícola? In: CONGRESSO BRASILEIRO DE CIÊNCIA DO SOLO, 21., 1987, Campinas. A responsabilidade social da ciência do solo - microbiologia do solo: só simbiose? Campinas: SBCS, 1988. p.337-352.

SORENSEN, M. Yam bean: Promoting the conservation and use of underutilized and neglected crops. 2. Rome: International Plant Genetic Resources Institute, 1996. $141 \mathrm{p}$

STAMFORD, N.P.; MEDEIROS, R.; MESQUITA, J.C.P. Avaliação de estirpes de rizóbio para jacatupé em regime de temperatura elevada. Revista Brasileira de Ciência do Solo, Campinas, v.19, p.49-54, 1994.
STAMFORD, N.P.; NEPTUNE, A.M.L.; SILVA, I.P. Efeito do potássio em presença de $\mathrm{N}$-mineral na nodulação, crescimento e absorção de nutrientes por (Vigna unguiculata (L.) Walp.) . Revista Brasileira Ciência do Solo, Campinas, v.4, p.99-103, 1980.

STAMFORD, N.P.; SANTOS, D.R.; LOPES, A.J.R Rendimento e teor de nutrientes por cultivares de caupi em Latossolo Vermelho-Amarelo com diferentes modos de aplicação do fertilizante. Revista Brasileira de Ciência do Solo, Campinas, v.14, p.5761,1990

STAMFORD, N.P.; SILVA, N.J. Efeito do magnésio na fixação do nitrogênio e no crescimento de (Vigna unguiculata (L.) Walp.), em um Latossolo Vermelho-Amarelo. Anais da Universidade Federal Rural de Pernambuco, Recife, v.6, p.35-42, 1981.

VINCENT, J.M. A manual for the practical study of root nodule bacteria. Oxford: Blackwell Science Pub., 1970. 164p.

ZEHLER M.E.; KREUPE, M.; GETHING, P.A. Sulfato de potássio e cloreto de potássio - sua influência na produção e na qualidade das plantas cultivadas. Campinas: Fundação Cargill, 1986. 111p. 